\title{
Assessment by non-destructive testing of new coating mortars for retrofitting the Architectural Heritage
}

\author{
I. Palomar, G. Barluenga \& J. Puentes \\ Department of Architecture, University of Alcala, Spain
}

\begin{abstract}
Repairing or replacing the traditional coating lime-based mortars is a common measurement to retrofit building facades. The use of appropriate techniques and materials according to the originals is essential to ensure architectural values and to preserve the Architectural Heritage. Consequently, it is necessary to investigate the microstructure and properties of both traditional and today's mortars by proper characterization. Non-destructive testing techniques (NDT) are always preferred because they can be tuned in the laboratory and also applied to evaluate on-site performance. In this paper, the assessment of lime-cement repair mortars' microstructure and performance is carried out using NDT by ultrasonic pulses (US). Ten lime-cement mortars were designed using: hydrated lime; white cement; gap-graded siliceous aggregate $(2-3 \mathrm{~mm})$; three lightweight aggregates, expanded clay, perlite and vermiculite; two types of short fibres, cellulose and polypropylene. The samples were evaluated with compression and shear US waves (P- and S- respectively). Transmission times (UPV), compressive modulus (M), shear modulus (G), dynamic Young modulus (E), bulk modulus (K) and Poisson's ratio (v) were obtained. The raw US signals were also analysed by Hilbert transformation (HT) and Fast Fourier transformation (FFT). HT facilitated $\mathrm{P}$ - and S-wave transmission time measurements while FFT simplified the evaluation of US attenuation. Then, bulk density, open porosity, capillary absorption, thermal conductivity, acoustic absorption and compressive and flexural strength of samples were compared to the US parameters. NDT by ultrasonic pulses showed very good correlations with hardened properties and demonstrated to be a useful tool for predicting the physical and mechanical performance of lime-cement repair mortars.
\end{abstract}

Keywords: lime-cement mortar, NDT, ultrasonics, physical properties. 


\section{Introduction}

Conservation and retrofitting of Built Heritage require a cluster of actions to characterise the general and specific properties of each building material. Regarding wall coatings, it is a common practice to repair or replace the historic mortars using today's ones. Consequently, it is necessary to assess these new mortars at the site, using accurate techniques to ensure the characteristics are respectful to the historic materials. Among characterization techniques, nondestructive testing (NDT) are preferred, because they can be tuned at the laboratory and also applied to evaluate on-site performance. In this paper, ultrasonic testing (US) based on stress-wave propagation through a porous material is used to evaluate repair mortars' properties. Two types of US waves were used: compression and shear waves, also called P- and S-waves. Then, two parameters were chosen to evaluate these waves: direct transmission time and attenuation, both with P-wave 54 and combined P- and S-waves $250 \mathrm{kHz}$ ultrasonic transducers. The transmission time depends on the elastic properties and the density of the material, whereas attenuation is related to frequency and absorption of the mixtures [1].

Another study was carried out previously to design and characterise the hardened properties of lime-cement mortars which included gap-graded aggregates (GGA), lightweight aggregates (LWA) and cellulose and PP fibres [2]. The assessment included early age cracking, mechanical, physical and acoustic and thermal performance. A parametric analysis of those results allowed to detect some relations: open porosity, early age shrinkage and cracking risk were related to water to binder ratio; mechanical and acoustic properties were affected by open porosity; thermal conductivity depended on density [3].

Thus, this paper focuses on the assessment of properties by portable NDT which allowed to compare those measurements with destructive or non-portable tests' results. Therefore, predictive models based on US parameters could be described.

\section{Materials and compositions}

A mixture of a hydrated lime class CL 90-S (UNE-EN 459-1:2011) and a white cement BL (UNE 80305), type II/B-L 32.5 N (UNE-EN 197-1:2011), supplied by Readymix-Asland S.A, was used. A normal-weight siliceous gap-graded aggregate $(2-3 \mathrm{~mm})$ and three lightweight aggregates (LWA) were also studied: expanded clay (A), perlite (P) and vermiculite (V). Two types of short fibres were considered: a cellulose fibre (FC) of $1 \mathrm{~mm}$ length - Fibracel ${ }^{\circledR}$ BC-1000 (Ø20 $\left.\mu \mathrm{m}\right)$ - supplied by Omya Clariana S.L. and a polypropylene fibre (FPP) of $6 \mathrm{~mm}$ length

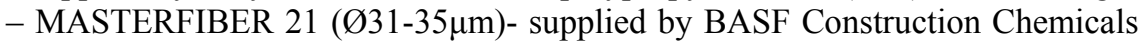
España S.L.

Table 1 summarizes the ten mortar compositions considered in the study. A reference lime-cement mortar with a siliceous gap-graded aggregate (GGA) was prepared (REFC). Then, 25 and $50 \%$ of GGA was replaced by expanded clay (A), perlite $(\mathrm{P})$ and vermiculite $(\mathrm{V})$. These mixtures were labelled as A25, P25, P50, 
V25 and V50. In addition, 1.5\% (FC15) and 3\% (FC30 and P25FC30) of cellulose fibre (FC) were also incorporated. At last, the mixture P25FPP incorporated $810 \mathrm{~g}$ of FPP per cubic meter of dried mortar. The binder (lime-cement) to aggregate ratio was 1:1:6 (cement: lime: aggregate) by volume in all cases. The water to binder ratio (w/b) was adjusted to get a plastic consistency and similar fresh workability for all the samples.

Table 1: Compositions of the lime-cement mortars (components in $\mathrm{kg}$ ).

\begin{tabular}{|c|c|c|c|c|c|c|c|c|c|c|}
\hline & REFC & FC15 & FC30 & A25 & P50 & $\mathrm{P} 25$ & $\begin{array}{c}\text { P25 } \\
\text { FC30 }\end{array}$ & $\begin{array}{l}\text { P25 } \\
\text { FPP }\end{array}$ & V50 & V25 \\
\hline BL-II B-L $32.5 \mathrm{~N}$ & 214 & 214 & 214 & 214 & 214 & 214 & 214 & 214 & 214 & 214 \\
\hline CL-90-S & 68 & 68 & 68 & 68 & 68 & 68 & 68 & 68 & 68 & 68 \\
\hline Cellulose fibres & - & 0.8 & 1.6 & - & - & - & 1.6 & - & - & - \\
\hline Polypropylene fibres & - & - & - & - & - & - & - & 0.81 & - & - \\
\hline Sand $2-3$ & 1502 & 1502 & 1502 & 1127 & 751 & 1127 & 1127 & 1127 & 751 & 1127 \\
\hline Expanded clay & - & - & - & 82 & - & - & - & - & - & - \\
\hline Perlite & - & - & - & - & 77 & 38 & 38 & 38 & - & - \\
\hline Vermiculite & - & - & - & - & - & - & - & - & 82 & 41 \\
\hline Water $^{\mathrm{a}}$ & 140 & 140 & 140 & 160 & 260 & 220 & 220 & 225 & 300 & 270 \\
\hline Water/binder $(\mathrm{w} / \mathrm{b})^{\mathrm{b}}$ & 0.56 & 0.56 & 0.56 & 0.61 & 0.96 & 0.83 & 0.83 & 0.85 & 1.10 & 1.01 \\
\hline
\end{tabular}

The ten fresh lime-cement mortars were characterised and early age shrinkage (24 h) and a mechanical and physical characterisation of the hardened mortars was carried out on $40 \times 40 \times 160 \mathrm{~mm}$ prismatic samples. Besides, the thermal conductivity $(\lambda)$ and sound absorption coefficient $\left(\alpha_{\text {NRC }}\right)$ were calculated. The experimental set-up and results have been previously published [3] and the data are summarised in Table 2.

The influence of $\mathrm{w} / \mathrm{b}$ ratio on early age behaviour (free shrinkage and early age cranking) and pore structure (open porosity and capillary water absorption) was

Table 2: Mechanical and physical properties of lime-cement mortar.

\begin{tabular}{|l|cccccccccc|}
\hline & REFC & FC15 & FC30 & \multirow{2}{*}{ A25 } & \multirow{2}{*}{ P50 } & P25 & P25 & P25 & \multirow{2}{*}{ V50 } & \multirow{2}{*}{ V25 } \\
\hline Shrinkage $(\mathrm{mm} / \mathrm{m})$ & 0.34 & 0.36 & 0.28 & 0.30 & 1.18 & 0.52 & 0.46 & 0.92 & 2.56 & 1.96 \\
B. Density $\left(\mathrm{kg} / \mathrm{m}^{3}\right)$ & 1880 & 1830 & 1840 & 1590 & 1450 & 1580 & 1670 & 1550 & 1420 & 1650 \\
O. Porosity $(\%)$ & 17.83 & 16.42 & 16.22 & 17.01 & 26.41 & 21.85 & 21.83 & 20.64 & 29.16 & 24.79 \\
Capillary $\left(\mathrm{kg} / \mathrm{m}^{2} \mathrm{~min}^{0.5}\right)$ & 0.53 & 0.65 & 0.55 & 0.50 & 1.08 & 0.88 & 1.07 & 0.83 & 1.30 & 1.48 \\
$\mathrm{~S}_{\text {COMP }}(\mathrm{MPa})$ & 6.17 & 9.67 & 7.67 & 7.83 & 6.33 & 6.67 & 6.33 & 5.83 & 3.00 & 5.00 \\
$\mathrm{~S}_{\text {FLEX }}(\mathrm{MPa})$ & 1.59 & 2.36 & 1.83 & 2.22 & 2.13 & 1.84 & 2.08 & 1.85 & 1.74 & 1.57 \\
$\lambda(\mathrm{W} / \mathrm{mK})$ & 0.368 & 0.190 & 0.429 & 0.322 & 0.175 & 0.220 & 0.442 & 0.287 & 0.204 & 0.267 \\
$\alpha_{\text {NRC }}(-)$ & 0.104 & 0.127 & 0.083 & 0.113 & 0.037 & 0.059 & 0.038 & 0.083 & 0.039 & 0.039 \\
\hline
\end{tabular}


identified [3]. It was highlighted that the inclusion of different components (GGA, LWA and fibres) varied the $\mathrm{w} / \mathrm{b}$ ratio required to achieve a plastic consistency. Consequently, w/b was defined as a good index to describe some relations related to changes in mortar compositions.

\section{Characterisation of lime-cement mortars by ultrasonic pulses}

Non-destructive testing (NDT) by ultrasonic pulses (US) was used to characterise two years old hardened samples with A PUNDIT Lab Ultrasonic device with ultrasonic P-wave $54 \mathrm{kHz}$ and $\mathrm{P}$ - and $\mathrm{S}$-wave $250 \mathrm{kHz}$ transducers. Three prismatic specimens $(40 \times 40 \times 160 \mathrm{~mm})$ of each composition were tested. Fig. 1 shows a typical S-wave raw signal $(250 \mathrm{kHz})$ and the value of the measured amplitude (A). Transmission times of $\mathrm{P}$ - and S-waves, $t_{P}$ and $t_{S}$ respectively, were identified using the Hilbert transformed wave [4]. In addition, raw signal in frequency domain obtained using the Fast Fourier Transformation (FFT) is plotted.
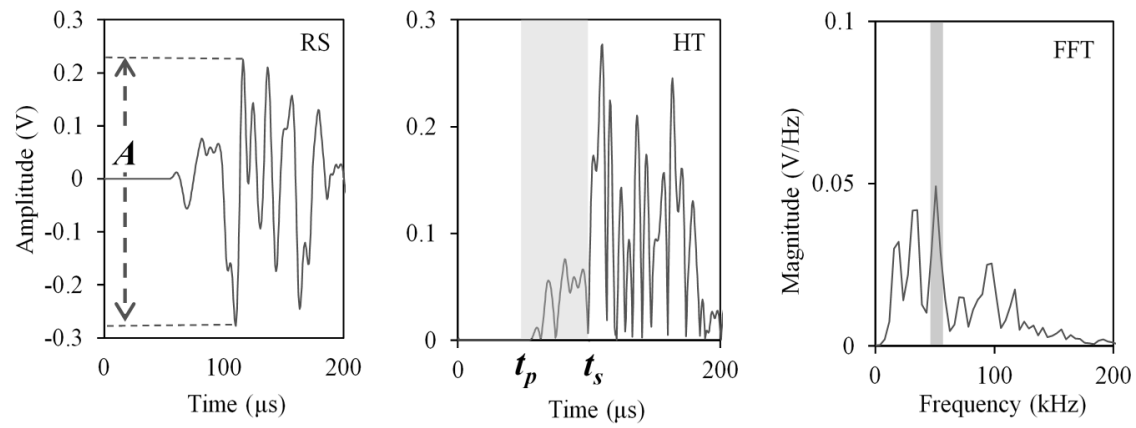

Figure 1: Typical S-wave raw signal $(250 \mathrm{kHz})$ through mortar in time $(\mathrm{RS})$, amplitude envelope (HT) and frequency domain (FFT).

Poisson's ratio (v), UPV compressive modulus (M), UPV shear modulus (G), dynamic Young modulus (E) and bulk modulus (K) were calculated, according to eqns. (1), (2), (3), (4) and (5) [5]. Where $\rho$ is the apparent (bulk) density $\left(\mathrm{g} / \mathrm{cm}^{3}\right)$ and $V_{P}$ and $V_{S}$ are the P- and S-wave velocity $(\mathrm{m} / \mathrm{s})$, respectively.

$$
\begin{gathered}
v=\left(0.5 V_{P}^{2}-V_{S}^{2}\right) /\left(V_{P}^{2}-V_{S}^{2}\right) \\
M=\rho V_{P}^{2} / 1000000 \\
G=\rho V_{S}^{2} / 1000000 \\
E=2 G(1+v)
\end{gathered}
$$




$$
K=\rho\left(V_{P}^{2}-\frac{4}{3} V_{S}^{2}\right) / 1000000 .
$$

Attenuation $A T(f)$ with 54 and $250 \mathrm{kHz}$ transducers was calculated using the amplitude $(A)$ of the raw US signal through the samples over a known path length $(x=160 \mathrm{~mm})$ versus the amplitude of face to face transducers $\left(A_{R}\right)$, according to eqn. (6) [1].

$$
A T(f)=-(20 / x)\left(\log \left(A / A_{R}\right)\right) .
$$

Table 3 summarizes the calculated results of apparent density ( $\rho)$, P- and Swave velocities at 54 and $250 \mathrm{kHz}\left(\mathrm{V}_{\mathrm{P}}\right.$ and $\left.\mathrm{V}_{\mathrm{S}}\right)$, UPV compressive modulus $(\mathrm{M})$, UPV shear modulus $(\mathrm{G})$, dynamic Young modulus (E), bulk modulus (K) and Poisson's ratio $(v)$.

The mixtures had $\mathrm{V}_{\mathrm{P}-54}$ and $\mathrm{V}_{\mathrm{P}-250}$ values ranging from 1990 to $3100 \mathrm{~m} / \mathrm{s}$. $\mathrm{V}_{\mathrm{P}-54}$ values were slightly lower than $\mathrm{V}_{\mathrm{P}-250}$ ones. UPV compressive modulus (M) was between 5 and $17 \mathrm{GPa}$ and UPV shear modulus (G) from 2 to $6 \mathrm{GPa}$. Dynamic Young modulus (E) ranged between 5 and $14 \mathrm{GPa}$ and bulk modulus (K) between 3 and $11 \mathrm{GPa}$. Moreover, two groups of values were identified: one comprising REFC, FC15, FC30 and A25 and another with the remaining mixtures. Compositions with cellulose fibres (FC15) showed the largest modules, whereas samples with an LWA (V50) showed the lowest ones. As expected, Poisson's ratio (v) varied between 0.20 and 0.31 , which meant that $\mathrm{V}_{\mathrm{P}-250}$ and $\mathrm{V}_{\mathrm{S}-250}$ were related.

Table 3: P-wave and S-wave UPV and attenuation results at 2 years.

\begin{tabular}{|l|cccccccccc|}
\hline & REFC & FC15 & FC30 & \multirow{2}{*}{ A25 } & P50 & \multirow{2}{*}{ P25 } & P25 & P25 & \multirow{2}{*}{ V50 } & \multirow{2}{*}{ V25 } \\
\hline Density $\left(\mathrm{g} / \mathrm{cm}^{3}\right)$ & 1.88 & 1.83 & 1.84 & 1.59 & 1.45 & 1.58 & 1.67 & 1.55 & 1.42 & 1.65 \\
$\mathrm{~V}_{\mathrm{P}-54}(\mathrm{~m} / \mathrm{s})$ & 2816 & 3013 & 2710 & 2855 & 2434 & 2440 & 2332 & 2378 & 1993 & 2200 \\
$\mathrm{M}_{54}(\mathrm{GPa})$ & 14.89 & 16.65 & 13.51 & 12.98 & 8.59 & 9.42 & 9.06 & 8.79 & 5.63 & 7.99 \\
$\mathrm{~V}_{\mathrm{P}-250}(\mathrm{~m} / \mathrm{s})$ & 3007 & 3083 & 2899 & 2954 & 2410 & 2472 & 2486 & 2546 & 2180 & 2331 \\
$\mathrm{~V}_{\mathrm{s}-250}(\mathrm{~m} / \mathrm{s})$ & 1597 & 1697 & 1616 & 1535 & 1412 & 1375 & 1324 & 1434 & 1306 & 1421 \\
$\mathrm{M}(\mathrm{GPa})$ & 16.98 & 17.43 & 15.47 & 13.89 & 8.42 & 9.67 & 10.30 & 10.08 & 6.73 & 8.97 \\
$\mathrm{G}(\mathrm{GPa})$ & 4.79 & 5.28 & 4.81 & 3.75 & 2.89 & 2.99 & 2.92 & 3.20 & 2.42 & 3.33 \\
$\mathrm{E}(\mathrm{GPa})$ & 12.49 & 13.55 & 12.25 & 9.87 & 7.16 & 7.64 & 7.60 & 8.10 & 5.90 & 8.02 \\
$\mathrm{~K}(\mathrm{GPa})$ & 10.60 & 10.39 & 9.06 & 8.89 & 4.57 & 5.68 & 6.40 & 5.82 & 3.51 & 4.53 \\
v $(-)$ & 0.30 & 0.28 & 0.27 & 0.31 & 0.24 & 0.28 & 0.30 & 0.27 & 0.22 & 0.20 \\
\hline \hline AT 54 (dB/mm) & 0.169 & 0.198 & 0.194 & 0.261 & 0.241 & 0.238 & 0.273 & 0.202 & 0.185 & 0.205 \\
AT 250 $(\mathrm{dB} / \mathrm{mm})$ & 0.112 & 0.120 & 0.108 & 0.127 & 0.108 & 0.103 & 0.175 & 0.157 & 0.098 & 0.087 \\
\hline
\end{tabular}

The results of attenuation are also reported in table 3 . Attenuation with $54 \mathrm{kHz}$ transducers, $A T$ (54), varied between 0.180 and $0.280 \mathrm{~dB} / \mathrm{mm}$, while $250 \mathrm{kHz}$ transducers, $A T$ (250), between 0.080 and $0.180 \mathrm{~dB} / \mathrm{mm}$. Mixtures with GGA or GGA and fibres (FC15 and FC30) and V50 showed the lowest values and mixtures with LWA and fibres (P25FC30 and P25FPP) had the largest $A T$ (250) values. 
Fig. 2 plots the four ultrasonic modules (USM), where linear relationships with a high positive correlation were identified between $\mathrm{K}$ and $\mathrm{M}$ and between $\mathrm{G}$ and E. Accordingly, K and E (one USM of each pair) were chosen to assess the physical properties of the lime-cement mortars.
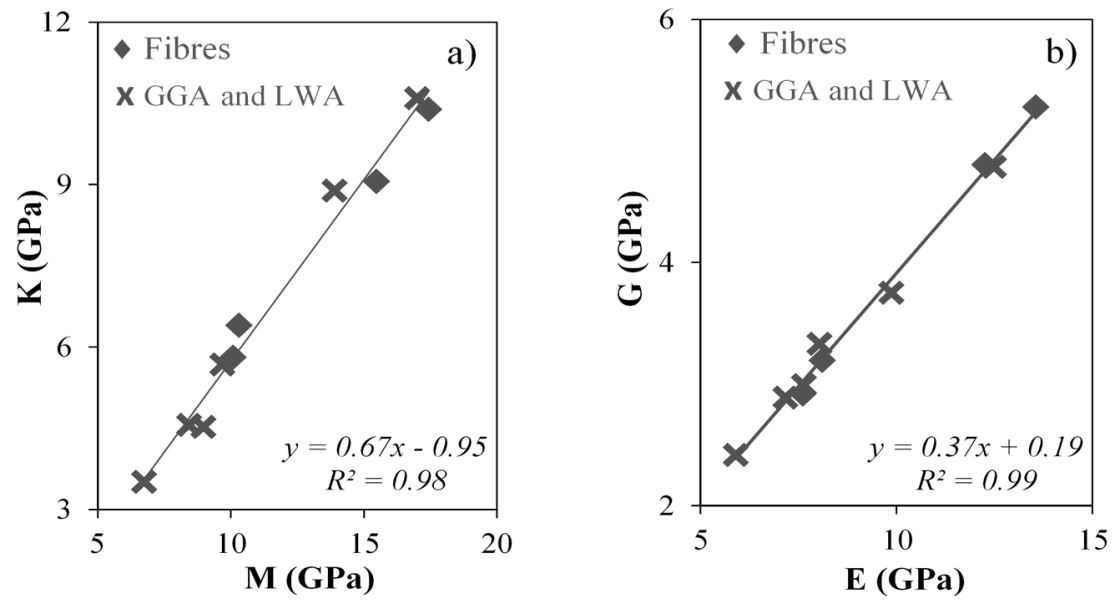

Figure 2: USM of lime-cement mortars: a) bulk modulus (K) vs. compressive modulus (M) and b) shear modulus (G) vs. Young modulus (E).
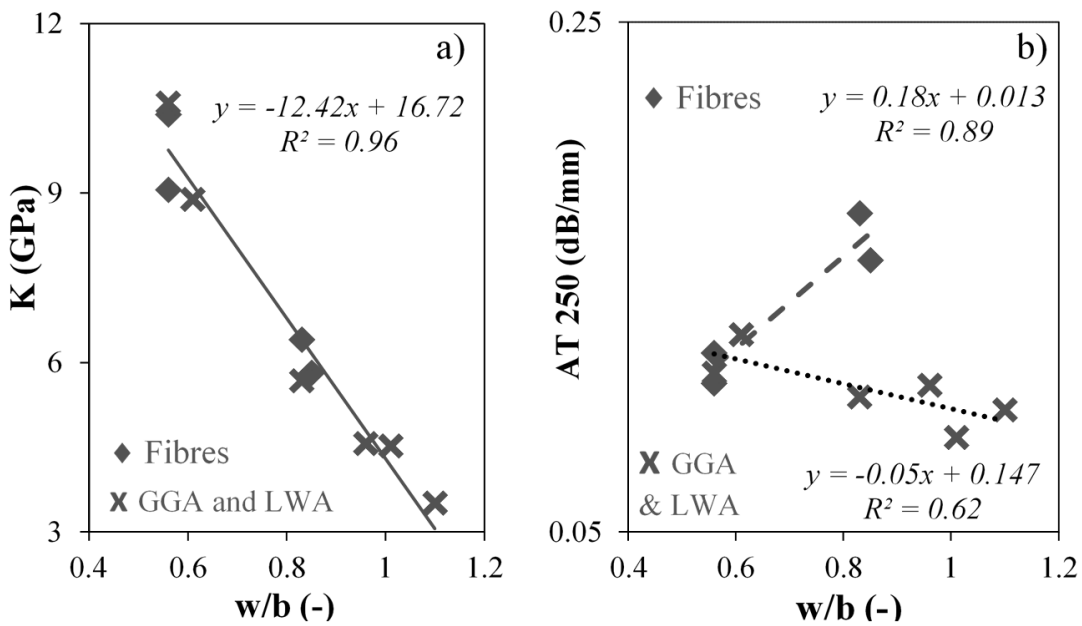

Figure 3: Relations among bulk modulus $(\mathrm{K})$ and attenuation versus $\mathrm{w} / \mathrm{b}$ ratio.

Due to the w/b ratio dependency on mortar composition, an evaluation US parameters regarding w/b was carried out (Fig. 3). An inverse linear relationship between w/b ratio and bulk modulus (K) was identified (Fig. 3a)). However, w/b ratio vs $A T$ (250) fitted with two different linear correlations depending on the compositions (Fig. 3b)): Compositions with fibres show a high positive 
correlation, whereas GGA and LWA mortars have a negative correlation. So this, it can be said that the composition has a remarkable influence in $A T$ (250), while $\mathrm{K}$ fitted a general trend for all the samples.

\section{Assessment of mortar physical properties by US measuring}

In a previous study [3], open porosity and capillary were used to evaluate the changes on the pore network and structure due to the mortar compositions. Then, those parameters were compared to identify how the microstructural changes affected mechanical, thermal and acoustic performance. It was observed that open porosity influenced acoustic performance, while bulk density affected thermal conductivity [3].

To compare physical properties and US parameters, bulk modulus (K), dynamic Young modulus (E) and attenuation (AT 250) were chosen. Both modulus showed similar trends, however $\mathrm{K}$ allowed better adjustment, except for bulk density.

Fig. 4 plots open porosity and capillary water absorption versus bulk modulus (K) and attenuation (AT 250). Two groups of compositions were identified according. A power adjustment was defined for both physical parameters regarding bulk modulus (K) (Figs $4 \mathrm{a}), 4 \mathrm{c})$ ), while two different relations where found when compared to attenuation (Figs 4b), 4d)). The compositions with fibres showed inverse linear relationships, while the compositions with GGA and LWA (and without fibres) showed a positive correlation.

According to Fig. 5, bulk modulus $(\mathrm{K})$ can be related to thermal and acoustic performance. Thermal conductivity $(\lambda)$ and $\mathrm{K}$ were directly related for compositions with GGA and LWA (and without fibres). However, this relation could not be found in the compositions with fibres. Noise reduction coefficient $\left(\alpha_{\mathrm{NRC}}\right)$ increases with the increase in bulk module $(\mathrm{K})$ for all samples.

Bulk density, dynamic Young modulus (E) and AT (250) were analysed together. Fig. 6 shows two linear relations: the first one is a simple linear relation, while the second one is more complex and include E and AT (250). Bulk density and dynamic Young modulus showed a direct relationship for all compositions (Fig. 6a)). However, two high positive correlations are shown in Fig. 6b), where the use of $A T$ (250) and E against bulk density separates compositions with GGA and LWA from mortars with fibres.

Summarising, it was found that the main hardened properties of the mortars studied could be assessed using NDT. Evaluating mortars by US allows to establish different relations within the physical, thermal and acoustic properties previously measured. It also has been able to find different trends when working with propagation velocities or attenuation modules. 

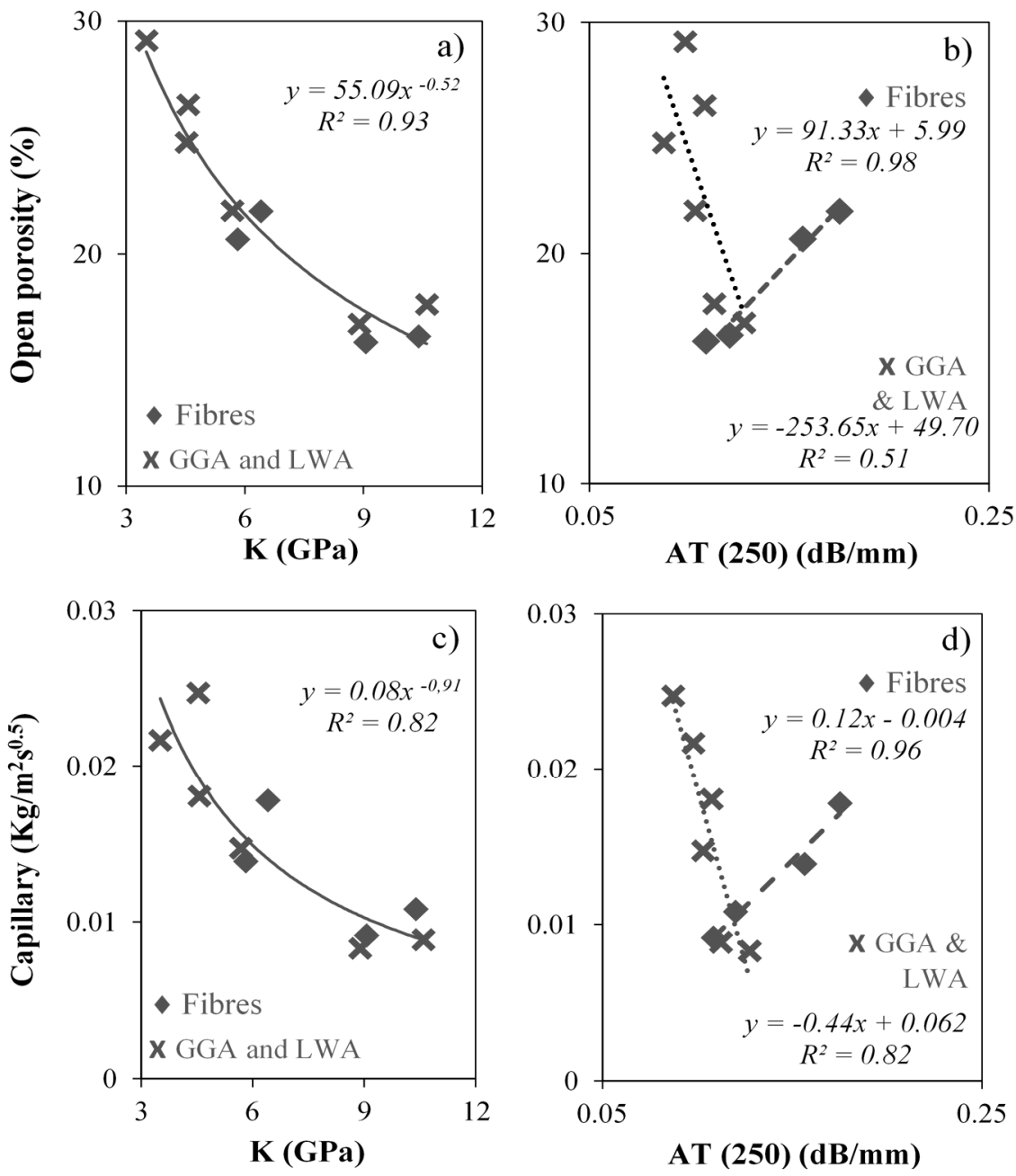

Figure 4: $\quad$ Physical properties - open porosity and capillary - against ultrasonic parameters - bulk modulus (K) and attenuation (AT). 

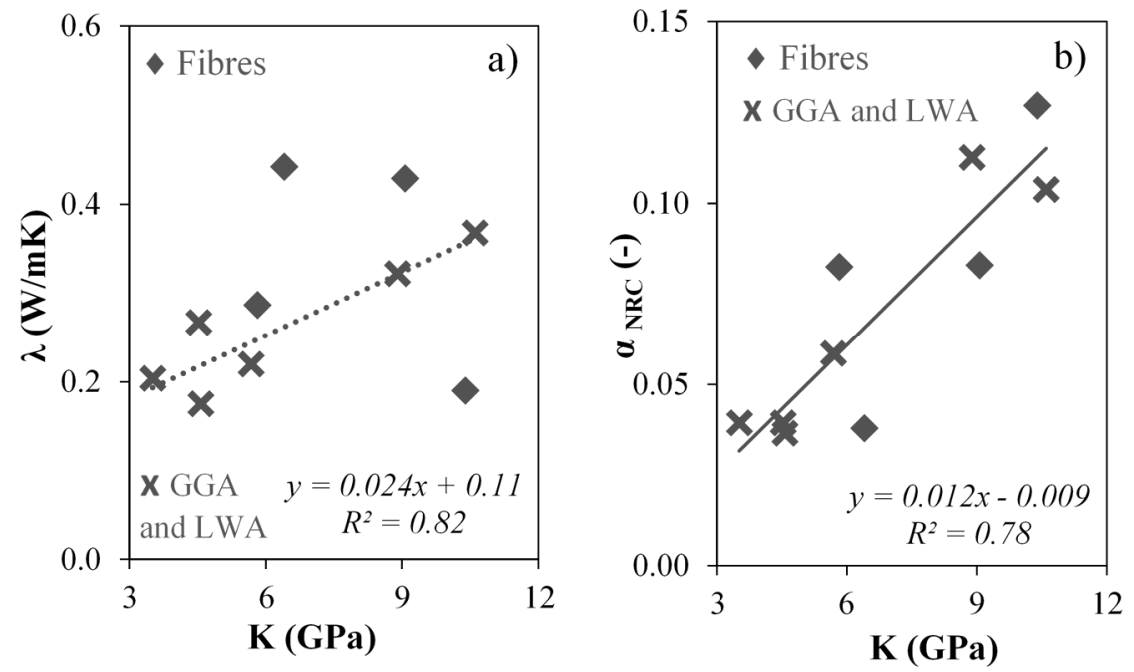

Figure 5: Thermal $(\lambda)$ and acoustic $\left(\alpha_{\mathrm{NRC}}\right)$ performance versus bulk modulus $(\mathrm{K})$.
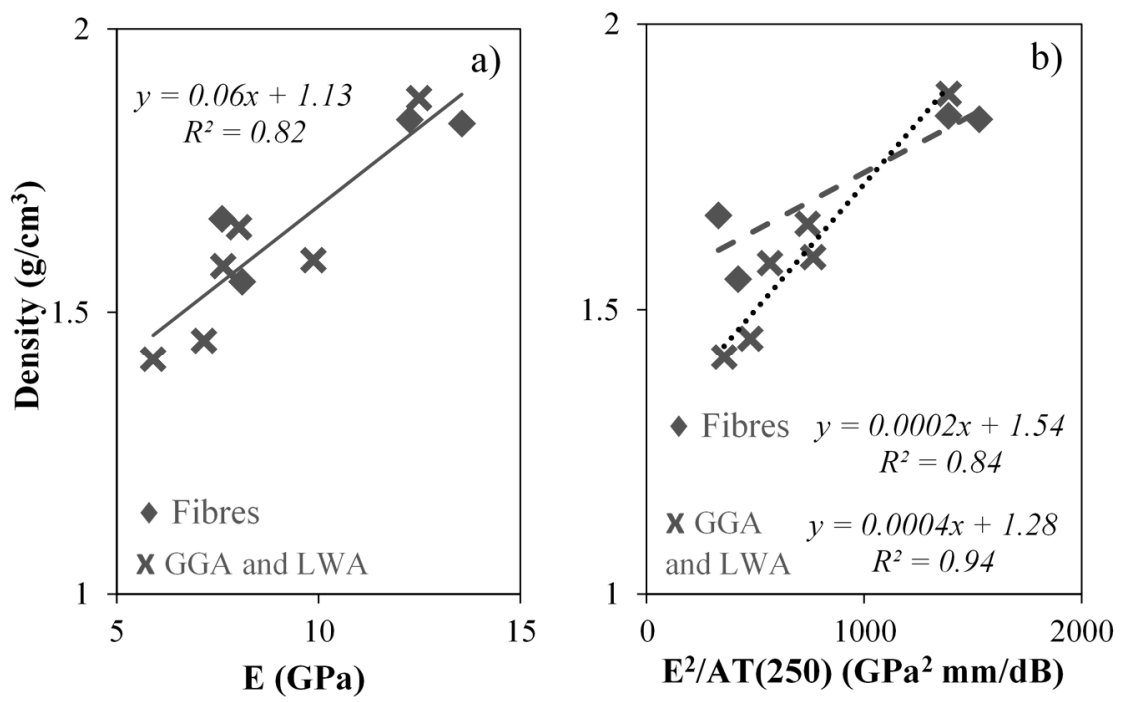

Figure 6: Bulk density vs. dynamic Young modulus (E). 


\section{Conclusions}

This paper presents the assessment of lime-cement repair mortars physical properties and performance using NDT by ultrasonic pulses (US). Regarding the US technique, it was observed that ultrasonic modules (USM) can be grouped in two groups with a high positive correlation- $M$ with $\mathrm{K}$ and $\mathrm{G}$ with $\mathrm{E}$ - while Poisson's ratio $(v)$ could not be related to them. In addition, US attenuation with 54 and $250 \mathrm{kHz}$ transducers were not related. S-wave raw signal $(250 \mathrm{kHz})$ through mortars allowed to identify separately the behaviour of mixture with fibres, especially when pore structure was assessed.

Regarding to the relationships found out between US parameters and the hardened properties, very good correlations were identified between the bulk modulus $(\mathrm{K})$ and water to binder ratio $(\mathrm{w} / \mathrm{b})$, open porosity, capillary water absorption and acoustic absorption $\left(\alpha_{\mathrm{NRC}}\right)$. Thermal conductivity $(\lambda)$ and $\mathrm{K}$ were linearly related, except for mortars with fibres.

However, dynamic Young modulus (E) was strongly affected by bulk density $(\rho)$. A more complex relation among E, $\rho$ and attenuation with $250 \mathrm{kHz}$ shear transducers (AT 250) was identified.

According to this results, predictive models based on US parameters could be described, allowing an on-site evaluation of this type of mortars.

\section{Acknowledgements}

The authors want to acknowledge the financial support for this research, provided by the Grant for training of Lecturers (FPU-UAH 2013), funded by the University of Alcalá, and the Research Program Geomateriales (S2009/Mat-1629), funded by the Comunidad de Madrid. Some of the components were supplied by BASF Construction Chemicals España S.L., Omya Clariana S.L. and Readymix-Asland S.A.

\section{References}

[1] Philippidis, T.P. \& Aggelis, D.G., Experimental study of wave dispersion and attenuation in concrete. Ultrasonics, 43, pp. 584-595, 2005.

[2] Palomar, I., \& Barluenga, G., Mezcla de cal y cemento con características térmicas y acústicas. Application number P2014-00305. Spain: OEPM, 2014.

[3] Palomar, I., Barluenga, G. \& Puentes, J., Lime-cement mortars for coating with improved thermal and acoustic performance. Construction and Building Materials, 75, pp. 306-314, 2015.

[4] Birgül, R., Hilbert transformation of waveforms to determine shear wave velocity in concrete. Cement and Concrete Research, 39, pp. 696-700, 2009.

[5] Boumiz, A., Vernet, C. \& Cohen Tenouj, F., Mechanical Properties of Cement Pastes and Mortars at Early Ages - Evolution with Time and Degree of Hydration. Advanced Cement Based Materials, 3, pp. 94-106, 1996. 